\title{
AVALIAÇÃO PAISAGÍSTICA DE UM TRECHO DA RODOVIA PR-340, ANTONINA, PARANÁ, BRASIL
}

\author{
Lucas Rezende Gomide ${ }^{1}$, Epitágoras Rodson Oliveira Costa ${ }^{2}$, Ana Paula Corrazza ${ }^{3}$, Daniela Biondi ${ }^{4}$ \\ ${ }^{1}$ Eng. Florestal, Dr., Depto. de Engenharia Florestal, UFVJM, Diamantina, MG, Brasil - lrgomide@ hotmail.com \\ ${ }^{2}$ Eng. Agrônomo, M.Sc., Volta Grande Reflorestamento, Rio Negrinho, SC, Brasil - epitagorascosta @uol.com.br \\ ${ }^{3}$ Bacharel em Turismo, M.Sc., SPVS, Curitiba, PR, Brasil - anapcorrazza@yahoo.com.br \\ ${ }^{4}$ Eng $^{\mathrm{a}}$ Florestal, Dr ${ }^{\mathrm{a}}$., Depto. de Ciências Florestais, UFPR, Curitiba, PR, Brasil - dbiondi@ufpr.br
}

Recebido para publicação: 06/10/2008 - Aceito para publicação: 08/03/2010

\begin{abstract}
Resumo
O estudo teve como objetivo compreender os agentes que compõem uma porção da paisagem na Área Particular Protegida Morro da Mina, e discutir o padrão visual paisagístico de um trecho da rodovia PR- 340, na região de Antonina - PR. Utilizou-se o método direto de análise da paisagem com as seguintes variáveis: vegetação, conservação do solo, relevo, ação antrópica e singularidade. Foram amostrados 20 pontos amostrais, com 3 repetições por ponto, distantes 200 metros entre si, sendo avaliados o lado direito e esquerdo da rodovia. No processamento das informações contou-se com as técnicas de análise de componente principal e a análise de agrupamento, para discriminar as áreas de grande interesse visual paisagístico e a variação paisagística. Constatou-se que a vegetação foi a variável mais representativa no percurso, independente do lado que se trafega. A qualidade da paisagem no lado esquerdo da rodovia foi influenciada pela vegetação e conservação do solo. O mapa de qualidade visual paisagística do trecho foi formado com três classes. Conclui-se que a predominância da paisagem do trecho da rodovia PR -340 tem a classe média de qualidade visual. Comparando os dois lados do trecho analisado, verificou-se que o lado esquerdo apresentou melhor conjunto de qualidades visuais paisagísticas.
\end{abstract}

Palavras-chave: Paisagem; RPPN; análise multivariada.

\begin{abstract}
Landscape evaluation of a sector of the PR-340 road, located in Antonina County, Paraná State, Brazil. The objective of this study was to understand the agents that compose a portion of the landscape from the "Protected Private Area Morro da Mina", and to discuss the landscape visual standard of a PR-340 road sector, in the region of Antonina, PR. The direct method of landscape analysis, with the following variables was used: vegetation, soil conservation, relief, anthropic action, and singularity. Twenty observation points were sampled, with 3 repetitions for point, 200 meters distant from each other. Both sides of the road were evaluated. In the information process the principal components technique analysis and the grouping analysis, with the intention to discriminate areas of great visual interest, as well as explaining the landscape variation, were used. It was evidenced that the vegetation was the most representative variable in the analyzed sector, regardless the traffic direction. The road left side was influenced by the vegetation and soil conservation. The landscape visual map was composed by three groups. It was concluded that the analyzed sector was classified as an intermediate visual quality landscape. Comparing the two edges of the analyzed road sector, it was observed that the left side presented, as a whole, higher landscape visual qualities.

Keywords: Landscape; conservation unit; multivariate analysis.
\end{abstract}

\section{INTRODUÇÃO}

O Brasil é conhecido mundialmente por sua exuberante natureza e diversidade de fauna e flora, contando ainda com uma rica variação de ambientes, que se estende dos pampas gaúchos, passando por floresta atlântica, cerrado, caatinga e chegando à floresta Amazônica. Essa grande matriz paisagística é permeada por um número elevado de estradas vicinais, que promovem o crescimento e a ligação entre áreas do país. Essas estradas são elementos importantes, ligando diversas paisagens entre si, mostrando os 
aspectos antrópicos, principalmente nas áreas lindeiras às rodovias (BIONDI, 2002). O Brasil apresenta uma malha viária de $1.876 .479,20 \mathrm{~km}$, sendo mais concentrada nas regiões Sudeste e Sul do país. O Paraná, por sua vez, apresenta um contingente de $265.261,40 \mathrm{~km}$ de estradas municipais, estaduais e federais, o que corresponde a 14,13\% do total brasileiro (DNIT, 2000).

A partir desses dados, percebe-se o quanto essas paisagens sofrem com os impactos provenientes das estradas. Segundo Formam; Godron (1995), a paisagem é uma estrutura heterogênea, formada por um complexo de unidades que integram a vegetação, o solo e atividades humanas. De acordo com Guidelines (1995), a não-atração do observador por uma paisagem pode ser refletida pela presença de impacto visual. Esse tipo de impacto geralmente está relacionado a uma série de fatores, como alterações no solo, expansão da área urbana, mineração, agricultura, reflorestamentos, desmatamento, redes de transmissão e áreas industriais, entre outros. Segundo o mesmo autor, a significância do impacto visual sobre a paisagem é uma função da sensibilidade do observador em perceber as mudanças e alterações. Essa sensibilidade incorpora questões ligadas a tolerância e valoração da paisagem para cada observador.

Desta maneira, a visão pode ser considerada como um dos principais sentidos que os seres humanos apresentam, sendo responsável por distinguir uma grande variação de cores, textura, profundidade espacial, servindo ainda como um importante guia nas escolhas e percepções humanas.

A percepção da paisagem pelo homem é caracterizada pela organização de informações obtidas através dos sentidos, sendo composta pelos seguintes agentes: os elementos naturais ou artificiais presentes no cenário, o espectador que realiza o plano de visualização e o processo de interpretação da paisagem. A união desses três processos fornece ao ator/executor o sentimento de compreensão e valoração da paisagem (ARTHUR, 1977).

Mesmo apresentando problemas ligados à intervenção humana, uma paisagem só existe se existir um observador para apreciá-la, sendo suas interpretações e análises feitas por intermédio dos sentidos e da percepção de cada um, conforme comentam Meneses (2002) e Dalavale; Zanin (2003). Nesse aspecto, a paisagem deve refletir a realidade de um local em determinado período e os signos culturais que povoam o imaginário das pessoas (CRUZ, 2002). A atração humana pela paisagem é descrita em diversos estudos, como os encontrados em Tuan (1980), Fernandes (2002), Andrade; Santos (2005) e Xavier (2005).

Segundo Vargas et al. (2004), a fase de avaliação da paisagem pode ser entendida como uma completa descrição e análise dos recursos ambientais e suas interações. Ainda segundo os autores, ao se realizar a caracterização da situação ambiental, deve-se englobar um levantamento de campo, interpretação e análise da situação da área. Um dos métodos encontrados na literatura, definido como método direto, considera o aspecto do contato direto com a paisagem para a realização das análises. Biondi; Leal (2002) afirmam que o método direto é um dos mais utilizados para estudos paisagísticos. Os autores empregaram o método para a avaliação visual paisagística de trilhas no parque estadual de Vila Velha, em Ponta Grossa (PR). Gonzaga et al. (2004) utilizaram o método direto na valoração da paisagem do Parque Municipal do Passaúna, em Curitiba (PR), com locação de pontos distanciados em 200 metros entre si, para avaliação visual paisagística de 7 variáveis selecionadas.

Serrão (2005) sugere pensar na natureza a partir da estética, estabelecendo uma articulação entre natureza e paisagem, mostrando as singularidades de seu conjunto, ou a singularidade dos diversos seres que a formam. Esses esforços em modelar a paisagem são tendências ligadas à necessidade de respostas, pois, com o entendimento desses processos dinâmicos, o manejo da paisagem será mais facilmente aplicado.

Considerando-se a hipótese de que através da análise dos componentes da paisagem é possível discriminar as áreas de grande variação paisagística e interesse visual para a sua conservação e manejo, o objetivo do trabalho foi avaliar e distinguir as diferentes paisagens de um trecho da rodovia PR-340, que atravessa a Reserva Natural do Morro da Mina, no estado do Paraná. Para alcançar esse objetivo, a pesquisa buscou compreender as relações entre as variáveis (vegetação, conservação do solo, relevo, ação antrópica e singularidade/atratividade) que ditam o padrão paisagístico local, para ambos os lados da rodovia, e indicar áreas com relevância paisagística aos motoristas que trafegam no referido trecho.

\section{MATERIAL E MÉTODOS}

\section{Área de estudo}

A área de estudo encontra-se localizada dentro dos limites periféricos da Reserva Natural do Morro da Mina, administrada pela Sociedade Proteção de Vida Selvagem (SPVS). A estrada selecionada pertence a um trecho da rodovia PR-340, que permeia e usufrui da paisagem da Reserva, nos municípios 
de Antonina e Morretes (Figura 1). O clima da região é caracterizado como Af - tropical super-úmido e sem seca -, segundo a classificação Köppen. Nesse local são observadas duas paisagens bem definidas: a planície litorânea e a Serra do Mar, sendo o contato entre essas duas paisagens perfeitamente delineável (SPVS, 1999).

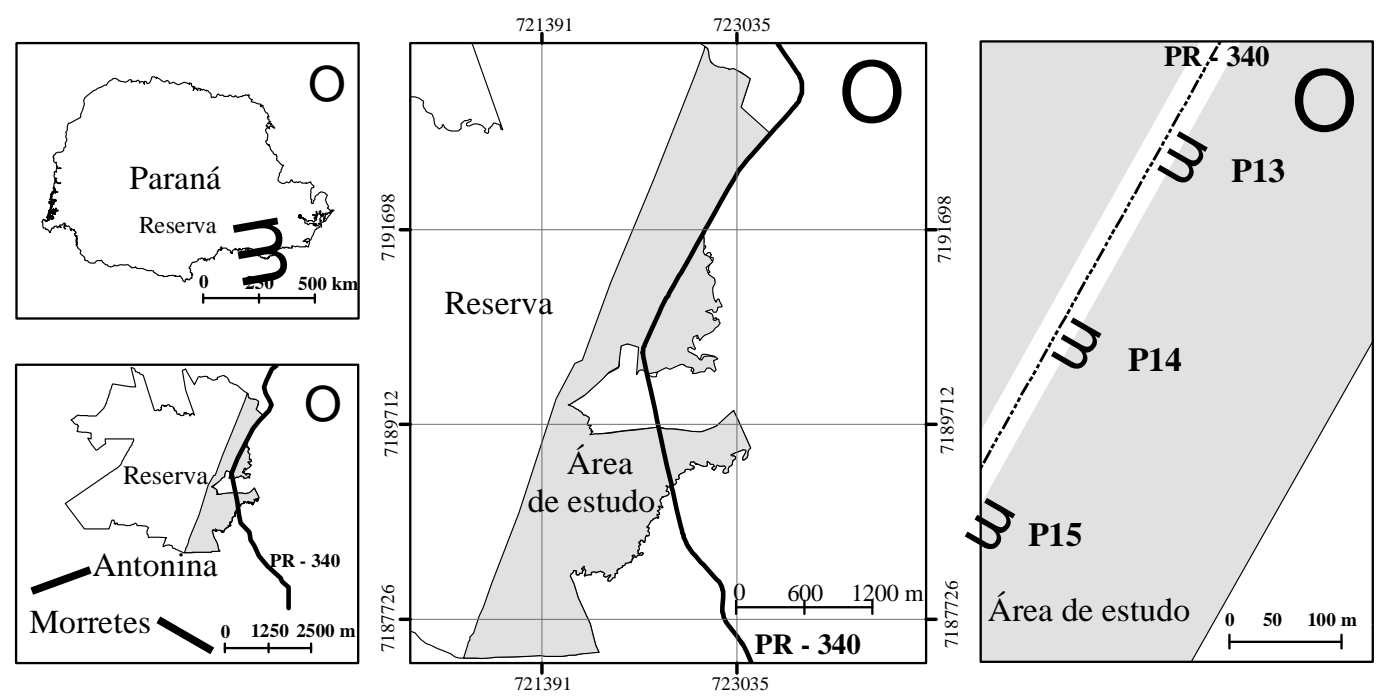

Figura 1. Localização da área de estudo - Reserva Natural do Morro da Mina, Paraná.

Figure 1. Localization of the study area - Reserva Natural do Morro da Mina, Paraná.

O local é banhado por diversos cursos d'água, que nascem no interior da reserva ou em suas proximidades. Na porção serrana formam uma rede hidrográfica adaptada às estruturas geológicas e às ocorrências de rochas de menor resistência à erosão. Já na zona de planície os rios apresentam um perfil de baixo curso, com meandros, seixos rolados e depósitos de areia, que sofrem influência das oscilações das marés nos seus finais de trecho.

Além disso, é observada uma fauna bastante representativa da Floresta Atlântica e de ecossistemas associados (SPVS, 1999). Segundo a mesma fonte, a maior parte da região litorânea, e em quase toda a área da Reserva, a vegetação original encontra-se bastante alterada em relação à floresta original, que sofreu forte exploração de madeira e minério de ferro. Apesar dessa forte ação antrópica no passado, ainda persistem, na reserva, remanescentes de unidades fisionômicas, como Formações Pioneiras de Influência Flúvio-marinha, Formações Pioneiras de Influência Fluvial, Floresta Ombrófila Densa Submontana e áreas ecotonais alteradas.

\section{Avaliação da paisagem}

A avaliação paisagística do trecho selecionado da rodovia PR-340 foi realizada pelo método direto, conforme Alonso (1995). O agente valorador dessa análise foi uma equipe de três pessoas, com observação direta (in loco) na área de estudo. No trecho da rodovia foram amostrados 20 pontos, com distâncias fixas de 200 metros entre si, sendo o mesmo valor de referência empregado por Gonzaga et al. (2004). A figura 1 apresenta um conjunto de pontos amostrais aplicados na área.

A partir da distribuição dos pontos amostrais, foi estabelecido um conjunto de variáveis relacionadas à paisagem que poderiam ser vistas pelos motoristas durante a viagem no trecho. Basicamente, foram levados em consideração os dois sentidos de trânsito da rodovia (pista esquerda e a pista direita), pois o interesse foi retratar a área adjacente à rodovia. Em termos de localização do trajeto, o lado direito representa a posição do motorista que trafega no sentido do Bairro Alto-Antonina; o lado esquerdo o sentido oposto.

Assim, em cada ponto amostrado foram analisados cinco variáveis presentes na paisagem local, que recebiam notas de acordo com a percepção do observador. As variáveis utilizadas e suas pontuações são descritas a seguir:

a) Vegetação - variável medida pela predominância na paisagem, nas seguintes categorias: (1) pastagens

FLORESTA, Curitiba, PR, v. 40, n. 4, p. 701-710, out./dez. 2010.

Gomide, L. R. et al. 
e vegetação bastante alterada em estado inicial de sucessão, (2) vegetação em estágio de sucessão de inicial a médio e (3) áreas mais conservadas que nas categorias anteriores.

b) Conservação do solo - variável composta pela combinação da declividade e do uso da terra. O termo conservação do solo, nesse caso, estava diretamente ligado à presença de cobertura vegetal, erosão, aterros, bem como outros fatores que possam causar uma lixiviação da imagem e qualidade da paisagem. Suas categorias foram: (1) baixa qualidade de conservação do solo, (2) média qualidade de conservação do solo e (3) satisfatória qualidade de conservação do solo.

c) Relevo - variável avaliada de forma visual pelos observadores, que apresentou as seguintes categorias: (1) relevo plano, (2) relevo levemente ondulado e (3) relevo acidentado, com presença de montanhas.

d) Ação antrópica - variável associada à presença e intervenção do homem ao ambiente natural. Apresentou as seguintes categorias: (1) linha de transmissão, (2) torre de transmissão, (3) placas de sinalização/outdoors, (4) construções, (5) resíduos/poluição e (6) outros aspectos que não se enquadravam nas categorias anteriores, tais como árvores exóticas à flora brasileira. A pontuação final dessa variável foi feita da seguinte forma: para cada categoria antrópica encontrada no ponto de visada foi descontado 1 ponto da nota máxima (6), e, no final, o valor residual foi empregado para pontuar o ponto amostral.

e) Singularidadelatratividade - variável relacionada ao grau de atração que o local tem em relação à população. As categorias de análise seguiram os critérios de Oliveira (2003): (1) baixa - não apresenta elemento natural ou antrópico que tenha destaque na paisagem, (2) média - apresenta elemento natural que chama a atenção do observador no contexto geral da paisagem e (3) alta possui presença de elemento com grande beleza cênica, embora não seja raro encontrá-lo em áreas semelhantes na região.

Essas variáveis foram transformadas em uma escala contínua $(0,1)$, para que todas tivessem o mesmo peso e importância dentro da paisagem. Na coleta dessas informações, foi considerada uma visada com perda de $30^{\circ}$ da visão do motorista, para um dos lados da pista (Figura.2). Segundo Biondi (2002), a percepção de paisagem por um motorista é $1 / 3$ a menos que a parcela visual destinada aos passageiros. Esse fato é devido à conduta do motorista, que requer atenção ao trânsito, limitando assim seu campo visual. Por essa razão, o tempo de observação do motorista para as paisagens não ultrapassou 30 segundos. Foram realizadas ainda três repetições para cada ponto selecionado, nos dois lados da rodovia, sendo em seguida calculada a média por ponto amostrado. As repetições foram coletadas por diferentes avaliadores, que seguiam as normas do trabalho.

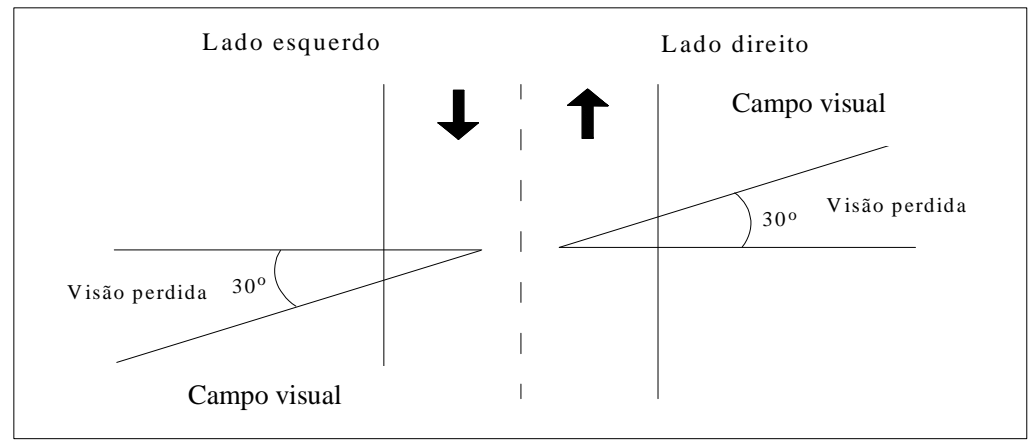

Figura 2. Campo visual do observador (motorista) durante a avaliação da paisagem.

Figure 2. Visual field of the observer (driver) during the evaluation of the landscape.

No processamento dos dados foi utilizada a análise multivariada e a correlação entre as variáveis, para definir melhor o comportamento de todas as variáveis do sistema. Assim, foram empregadas duas técnicas amplamente conhecidas na literatura: análise de componente principal (PCA) e análise de agrupamentos (cluster). A análise de componentes principais consiste essencialmente em reescrever as coordenadas das amostras em outro sistema de eixo mais conveniente para a análise dos dados, mostrando ainda quais variáveis são mais importantes para o sistema (paisagem). 
A análise de cluster é um processo de partição de uma população heterogênea em várias subclasses mais homogêneas, auxiliando na definição de conjuntos com características semelhantes (DONI, 2004). Nessa análise foi empregado o método de Ward, por ser o método hierárquico mais eficiente, conforme Trigo (2001), e aplicado por Gerhardt et al. (2001), Chiguty (2005) e Souza; Souza (2006), entre outros. A partir da formação das classes paisagísticas, definidas pela análise de agrupamento, foi desenvolvido um mapa contendo a classificação da paisagem em 3 classes (1 - pior paisagem, 2 - paisagem mediana e 3 - melhor paisagem).

\section{RESULTADOS E DISCUSSÃO}

A partir da PCA, percebeu-se que houve uma variação na ordem das variáveis que explica o comportamento da paisagem ao longo da rodovia. Observou-se que a vegetação é a variável que mais representa a mudança paisagística, para ambos os lados. Essas informações indicam que a vegetação foi a variável mais representativa ao longo do percurso, independentemente do lado em que se trafega. A respeito disso, Andrade (2002) constatou que as formações vegetais apresentam características que geralmente conferem a um lugar uma determinada especificidade dentro do conjunto da paisagem. Pires (1996) afirma que a paisagem se transforma rapidamente com a retirada da cobertura vegetal, com a modificação dos perfis naturais do terreno e com a poluição das superfícies d'água. Acrescenta ainda que tal transformação não só diminui a qualidade visual como traz uma série de problemas ambientais.

Considerando apenas o lado esquerdo, percebeu-se um equilíbrio entre a vegetação e o relevo, com valores de 39,72\% e 33,57\%, respectivamente (Figura 3). A explicação para esse equilíbrio está no fato de o motorista ter maior chance de apreciar o relevo local, o qual divide atenção junto à vegetação, e assim esse lado torna-se mais desejável ao desfrute, pois combina vegetação e relevo. A combinação desses elementos faz a paisagem ter unidade. Lucas (1991) afirma que a unidade numa paisagem é percebida quando os contrastes visuais numa composição parecem ser contrabalanceados por similaridades visuais.

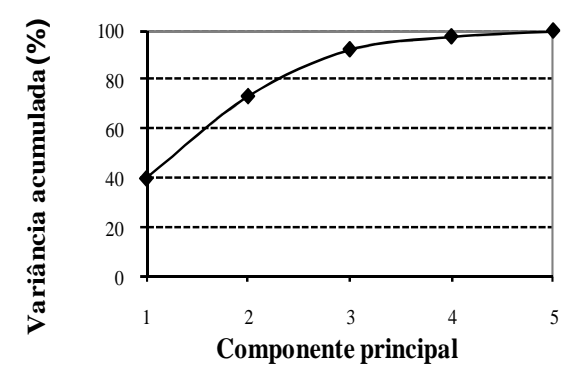

(a)

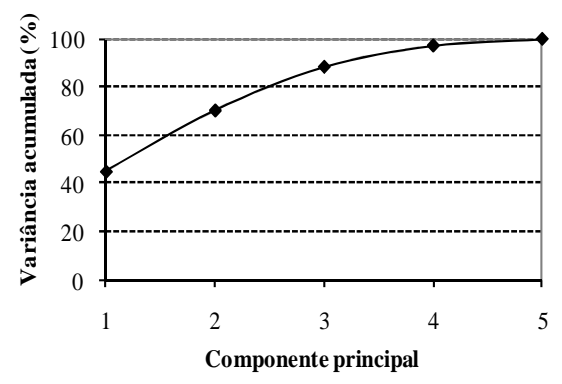

(b)

Figura 3. Variância acumulada em porcentagem das variáveis (1 - vegetação, 2 - conservação do solo, 3 relevo, 4 - ação antrópica e 5 - singularidade) do lado esquerdo (a) e direito (b) do trecho da rodovia PR-340.

Figure 3. Accumulated variance in percentage of the variable (1 - vegetation, 2 - conservation of the soil, 3 - relief, 4 - antropic action and 5 - singularity) of the left side (a) and right (b) of the stretch of highway PR-340.

A correlação entre as variáveis auxiliou na compreensão dos agentes modeladores do ambiente, e, nesse caso, as variáveis "conservação do solo" e "vegetação" apresentaram uma correlação positiva muito forte $(0,8386)$ no lado direito da rodovia (Tabela 1). Esse valor indica que, com o aumento da qualidade da vegetação, há um aumento na conservação do solo ao longo da rodovia para o lado direito, sendo um aspecto bastante importante para a manutenção da qualidade da paisagem. As demais variáveis não apresentaram correlações expressivas (acima de 0,5 ). 
Tabela 1. Correlação entre as variáveis analisadas no lado direito da rodovia PR-340.

Table 1. Correlation between the analyzed variable in the right side of highway PR-340.

\begin{tabular}{lccccc}
\hline & Vegetação & Conservação do solo & Relevo & Aspecto antrópico & Singularidade \\
\hline Vegetação & 1 & & & & \\
Conservação do solo & 0,8386 & 1 & & & \\
Relevo & 0,1898 & 0,3193 & 1 & & \\
Aspecto antrópico & 0,0991 & 0,1022 & $-0,1051$ & 1 & \\
Singularidade & 0,4095 & 0,4572 & $-0,2227$ & 0,1293 & 1 \\
\hline
\end{tabular}

Também no lado esquerdo essas duas variáveis (vegetação e conservação do solo) apresentaram um valor considerado alto entre as demais variáveis estudadas, com um valor de 0,5797 (Tabela 2). Entretanto as variáveis "relevo" e "singularidade" apresentaram uma maior correlação $(0,8393)$. Esse fato indica que, para o lado em questão, a "singularidade" da paisagem é aumentada à medida que a declividade do terreno aumenta. Em pesquisas que analisam a percepção de paisagem, é conhecido mundialmente o gosto das pessoas por paisagens em relevo acidentado. Segundo Tuan (1980), o relevo acentuado, como as montanhas e locais altos, exerce uma grande atração ao ser humano. Vargas et al. (2004) considera o relevo como um dos principais pontos a serem abordados em estudos ligados a paisagens.

Tabela 2. Correlação entre as variáveis analisadas no lado esquerdo da rodovia PR-340.

Table 2. Correlation between the analyzed variable in the left side of highway PR-340.

\begin{tabular}{lccccc}
\hline & Vegetação & Conservação do solo & Relevo & Aspecto antrópico & Singularidade \\
\hline Vegetação & 1 & & & & \\
Conservação do solo & 0,5797 & 1 & & & \\
Relevo & 0,063 & $-0,3311$ & 1 & 1 & 1 \\
Aspecto antrópico & $-0,03992$ & $-0,3369$ & 0,1244 & $-0,08568$ & 1 \\
Singularidade & 0,2522 & $-0,1511$ & 0,8393 & & \\
\hline
\end{tabular}

A alta correlação entre o relevo e a singularidade $(0,8393)$ indica que o motorista trafegando pelo lado esquerdo da rodovia PR-340 usufrui de melhores vistas da Reserva do Morro da Mina. As correlações entre vegetação $\mathrm{x}$ relevo, ação antrópica $\mathrm{x}$ singularidade, vegetação $\mathrm{x}$ ação antrópica $\mathrm{e}$ relevo x ação antrópica foram baixas, demonstrando não existir padrão comum de comportamento para a área.

A análise de agrupamento (cluster) gerada para os lados esquerdo e direito da rodovia contribuiu para a formação de três classes homogêneas, que correspondem à classificação qualitativa da paisagem: classe 1 - paisagem de pior qualidade visual, porque reúne as piores pontuações em relação às variáveis analisadas; classe 2 - paisagem de média qualidade visual, porque reúne as pontuações medianas relativas às variáveis; classe 3 - paisagem de melhor qualidade visual, porque reúne as melhores pontuações das variáveis analisadas.

Assim, utilizando os dados provenientes dos dois lados da rodovia e realizando uma única análise de agrupamento, o resultado gráfico da análise pode ser visto na figura 4. Dessa maneira, ao se promover um corte próximo ao ponto 2,5 do eixo das ordenadas, percebeu-se a formação das seguintes classes paisagísticas $(\mathrm{D}=$ lado direito e $\mathrm{E}=$ lado esquerdo): classe $1-5 \mathrm{D}, 6 \mathrm{D}$ e $17 \mathrm{D}$; classe $2-1 \mathrm{E}, 2 \mathrm{E}$, 3E, 4E, 5E, 6E, 7E, 8E, 9E, 10E, 11E, 12E, 13E, 14E, 15E, 1D, 2D, 3D, 7D, 8D, 9D, 10D, 11D, 12D, 13D, 14D, 15D, 16D, 18D, 19D e 20D; classe 3 - 16E, 17E, 18E, 19E, 20E e 4D.

A paisagem ao longo da rodovia pode ser enquadrada, de modo geral, na classe 2, pois grande parte dos pontos amostrais encontra-se nessa classe, algo em torno de $77,5 \%$ dos pontos totais, sendo um valor expressivo. Isso pode ser devido à localização do trecho da rodovia encontrar-se em uma área preservada, com poucas alterações na estrutura paisagística. Complementando esses resultados, com a soma dos pontos classificados na segunda e terceira classes, essa porcentagem passa para $92,5 \%$. Esse aumento de porcentagem reforça ainda mais o valor paisagístico do trecho analisado. Além disso, o lado esquerdo apresentou $100 \%$ de seus pontos distribuídos nas classes 2 e 3, o que demonstra uma superioridade do lado esquerdo frente ao lado direto, que contribui com $85 \%$ de seus pontos. 


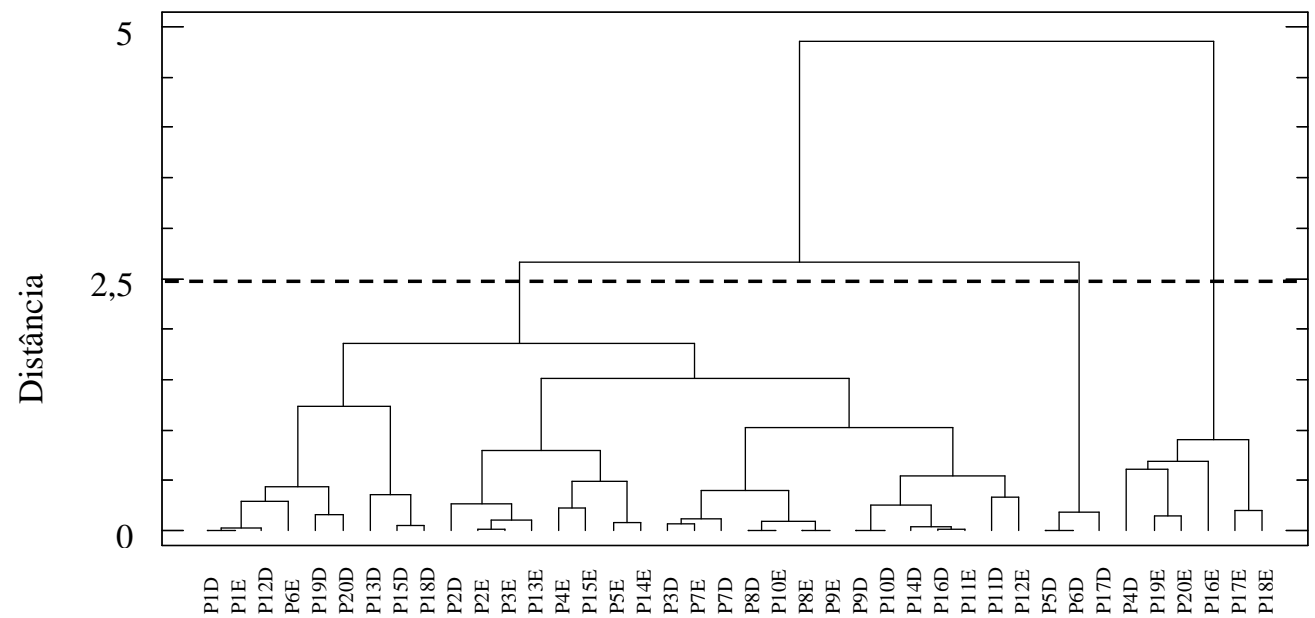

Figura 4. Gráfico da análise de agrupamento dos pontos amostrais na rodovia PR-340.

Figure 4. Graphic of the analysis of cluster of the sample points in highway PR-340.

A união dessas duas classes (2 e 3) dilui muito os efeitos de alguns pontos da classe mediana (2), com forte tendência para o classe 3 e vice-versa. Oliveira (2003) constatou esse mesmo efeito quando valorou as mesmas amostras pelo método direto e indireto. Esse autor observou que dentro da classe mediana há uma variação grande de notas, o que favorece fortes tendências para uma classe maior ou menor. No seu caso específico, a grande maioria da classe 2, quando avaliada in loco, acabou direcionada para uma classe superior.

Essa qualidade visual da paisagem provavelmente não deve gerar monotonia para o motorista, graças aos atrativos presentes na paisagem. Segundo Biondi (2002), a dinâmica de paisagens ao longo da rodovia é um aspecto muito importante para a segurança nas estradas. Além disso, a distribuição espacial da qualidade da paisagem ao longo da rodovia PR-340 permite detectar com precisão os trechos menos atrativos e que podem ser melhorados visualmente. Lucas (1991) afirma que diversidade na paisagem dá origem a interesses e contrastes, sem os quais tudo estaria em um plano secundário, mas se o número e $\mathrm{o}$ grau de contrastes for muito grande, a unidade se reverte em confusão e desarmonia.

Apenas uma pequena fração de pontos foi classificada como a pior área para o desfrute da paisagem, o que corresponde a apenas 7,5\% do total ao longo da rodovia. Os pontos pertencentes a essa classe apresentaram baixas notas nas variáveis vegetação, relevo e singularidade/atratividade, o que promoveu a sua baixa classificação.

Os pontos amostrais do lado esquerdo apresentaram uma classificação paisagística um pouco diferente do padrão expresso pelo lado direito, e esse comportamento foi esperado, já que são direções opostas de deslocamento pela rodovia. O lado esquerdo não apresentou nenhum ponto pertencente à pior classe paisagística, o que não ocorreu com o lado direito. Este resultado mostra um melhor padrão do lado esquerdo em atrair os olhares dos motoristas. Fato comprovado ao se analisar os membros da classe 3, que constam basicamente de 5 pontos, ou $83,3 \%$ dos pontos pertencentes a esse lado. O mapa de classificação da paisagem (Figura 5) apresenta o comportamento da qualidade da paisagem ao longo da rodovia.

Quando se analisou a classe 2 de qualidade visual paisagística, observou-se que o lado direito da rodovia contribuiu com $52 \%$ dos pontos e o lado esquerdo $48 \%$, valores considerados praticamente equilibrados. Se forem comparados quais pontos pertenceram a essa classe, observa-se que os pontos 1, 2 , $3,7,8,9,10,11,12,13,14$ e 15 faziam parte tanto do lado direito como do esquerdo. Esses pontos comuns aos dois lados da rodovia podem ser responsáveis pela harmonia local, conforme o princípio de composição paisagística denominado de repetição (BIONDI, 1990). 


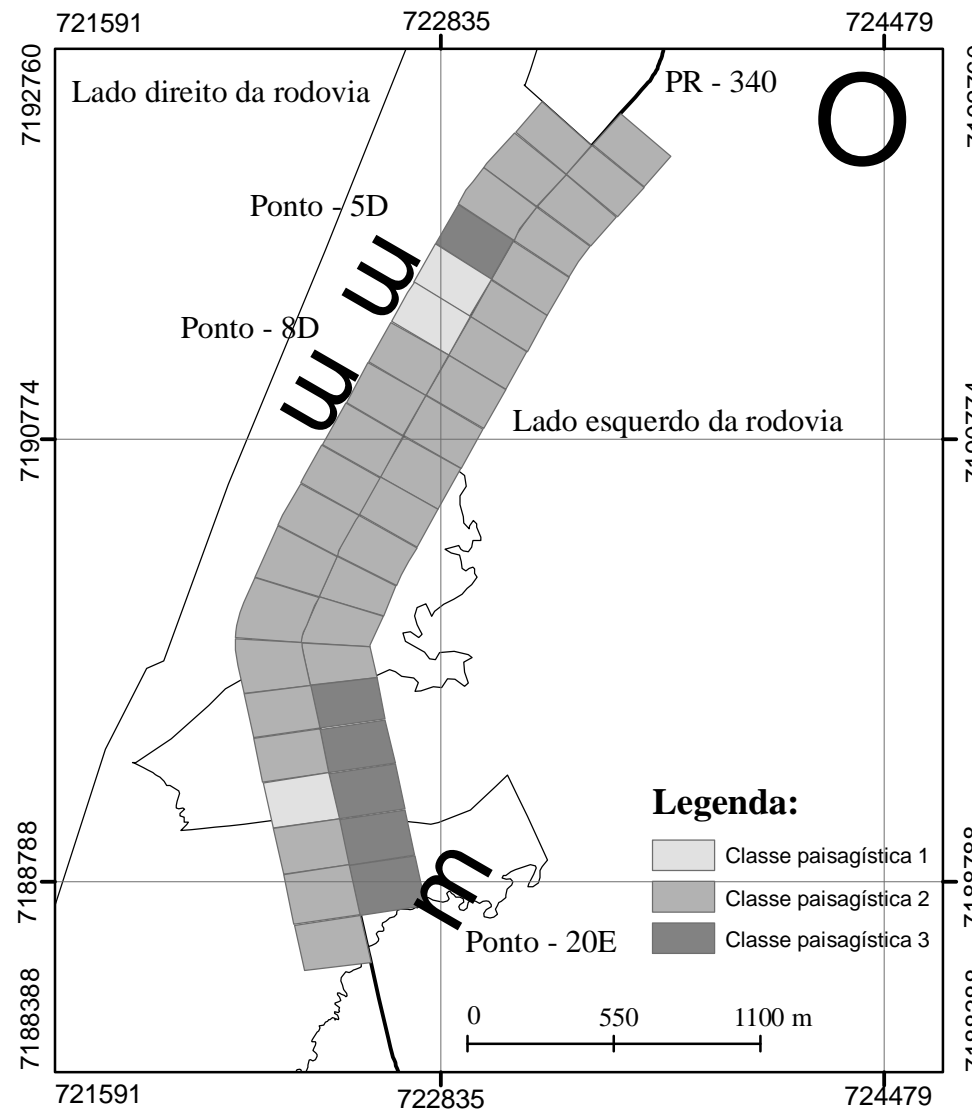

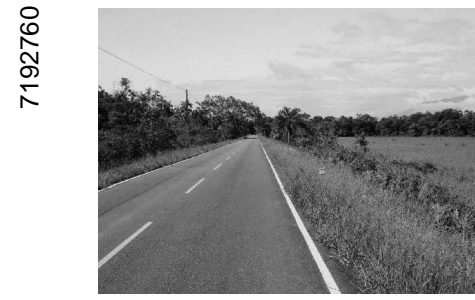

Ponto - 5D

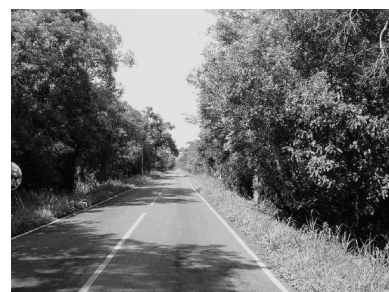

Ponto - 8D

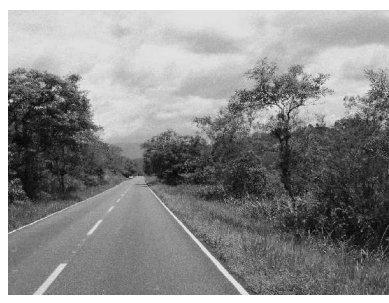

Ponto - 20E

Figura 5. Mapa da qualidade visual da paisagem ao longo da rodovia PR-340.

Figure 5. Map of the visual quality of the landscape throughout highway PR-340.

\section{CONCLUSÕES}

- A análise dos componentes da paisagem através da técnica e análise multivariada possibilitou a distinção das áreas de grande variação paisagística e interesse visual no trecho da rodovia PR-340, Antonina/Paraná.

- Com base nas classes de qualidade visual paisagística, conclui-se que a predominância da paisagem do trecho da rodovia PR-340, Antonina/Paraná, foi caracterizada como de média qualidade visual, pois $75 \%$ de seus pontos amostrais foram classificados na classe 2.

- O lado esquerdo do trecho da rodovia apresentou melhor conjunto de qualidades visuais paisagísticas quando comparado com o lado direito.

- A avaliação dos pontos amostrais do trecho da rodovia distribuídos no mapa de qualidade visual paisagística evidenciou, além dos melhores cenários vistos da rodovia, os locais que devem receber maior atenção para a recuperação e diminuição dos impactos visuais negativos existentes.

\section{REFERENCIAS}

ALONSO, M. A.; RHEA Consultores S. A. Guia para Elaboracion de Estudios del Medio Físico. Serie Monografía. Ministerio de Obras Públicas Transportes y Medio Ambiente. Editora Sucessores de Rivadeneyra, S. A. Valencia, 1995.

ANDRADE, S. M. O patrimônio histórico e arqueológico da Serra da Mesa: a construção de uma nova paisagem. 251 f. Tese (doutorado) - Universidade de São Paulo, São Paulo, 2002. 
ANDRADE, R. B.; SANTOS, R. J. Avaliação da organização espacial e infraestrutural dos atrativos turísticos naturais dos distritos de Uberlândia, MG, e seus impactos na população local. Disponível em <http://www.propp.ufu.br/revistaeletronica/edicao2005/humanas2005/avaliacao.PDF>. Acesso em 06/03/2006.

ARTHUR, L. M.; DANIEL, T. C.; BOSTER, R. S. Scenic Assessment: an overview. Landscape Planning. v. 4, p. 109-129, 1977.

BIONDI, D. Paisagismo. Recife: Imprensa da Universidade Federal Rural de Pernambuco. 1990. 184 p. . Seleção de espécies para o paisagismo rodoviário. Curitiba: FUPEF, 2002. 40p. (Série Técnica, n. 1).

BIONDI, D.; LEAL, C. T. Análise da capacidade paisagística do Parque Estadual de Vila Velha, PR. In: Congresso Brasileiro de Unidades de Conservação, 2, 2002, Fortaleza. Anais... Fortaleza: Rede Nacional Pró-Unidades de Conservação, Fundação O Boticário de Proteção à Natureza, Associação Caatinga, 2002. p. 359-367.

CHIGUTI, M. Aplicação da análise multivariada na caracterização dos municípios paranaenses segundo suas produções agrícolas. 209 p. 2005. Dissertação (Mestrado em Métodos Numéricos) - Setor de Ciências Agrárias, Universidade Federal do Paraná, Curitiba, 2005.

CRUZ, R. C. A. As paisagens artificiais criadas pelo turismo. In: Yázigi, E. (Org.). Turismo e paisagem. São Paulo: Contexto, 2002, p. 107-119.

DALVALLE, L. C.; ZANI, E. M. Avaliação da preferência por paisagens natural, rural e urbana - Estudo de caso: cidade de Erechim (RS) e entorno. In: Simpósio de Áreas Protegidas: Conservação no Âmbito do Cone Sul, 2, 2003, Pelotas, RS. Anais... Pelotas, 2003, p. 136-144.

DNIT, Departamento Nacional de Infraestrutura de Transporte, 2000. Disponível em <http:/www.dnit.gov.br/menu/rodovias/planejamentos>. Acesso em 20/09/2008.

DONI, M. V. Análise de cluster: métodos hierárquicos e de particionamento. São Paulo. Monografia. Universidade Presbiteriana Mackienzie. 93 p. 2004.

FERNANDES, G. J. P. A percepção didáctica da paisagem. De recurso pedagógico a objectivo educativo - O exemplo das áreas de montanha. In: Colóquio Psicologia Espaço e Ambiente, 1, 2002, Évora. Anais... Évora: Universidade de Évora. Disponível em <http://www.eventos.uevora.pt/cpea/Goncalo Fernandes.pdf >. Acesso em 08/03/2006.

FORMAN, R. T. T.; GODRON, M. Landscape Ecology. New York: John Wiley, 1986.

GERHARDT, E. J.; FINGER, C. A. G.; LONGHI, S. J.; SCHUMACHER, M. V. Contribuição da análise multivariada na classificação de sítios em povoamentos de Araucaria angustifolia (Bert.) O. Ktze., baseada nos fatores físicos e morfológicos do solo e no conteúdo de nutrientes da serapilheira. Ciência Florestal, Santa Maria, v. 11, n. 2, p. 41-47, 2001.

GUIDELINES for landscape and visual impact assessment, London: E \& FNSFON, 1995. 126 p.

GONZAGA, C. A. M.; WANDEMBRUCK, A.; SEGER, C. D.; BIONDI, D. Análise paisagística da trilha recreativa do Parque Municipal do Passaúna, Curitiba, PR. Cadernos de Biodiversidade, Curitiba, v. 4, n. 2, p. 66-73, 2004.

LUCAS, O. W. The design of forest landscapes. New York: Oxford University Press, 1991. 381 p.

MENESES, U. T. B. A paisagem como fato cultural. In: Yázigi, E. (Org.). Turismo e paisagem. São Paulo: Contexto, 2002, p. 29-64.

OLIVEIRA, D. A. Ecologia e valoração da paisagem do entorno da cidade de Paranaguá. 97 p. 2003. Dissertação (Mestrado em Engenharia Florestal) - Setor de Ciências Agrárias, Universidade Federal do Paraná, Curitiba, 2003. 
PIRES, P. S. Paisagem litorânea de Santa Catarina como recurso turístico. In: Yázigi, E. (Org.). Turismo, espaço, paisagem e cultura. São Paulo: Hucitec, 1996, p. 161-177.

SERRÃO, A. V. Pensar a Natureza a partir da Estética. A Ética e os desafios do mundo contemporâneo. XIX Encontro de Filosofia. Associação de Professores de Filosofia. Coimbra, 2005. Disponível em <http://www.apfilosofia.org/documentos/pdf/A_V_Serrao_Pensar_Natureza.pdf $>$. Acesso em 06/03/2006.

SOUZA, A. L.; SOUZA. D. R. Análise Multivariada para a estratificação volumétrica de uma Floresta Ombrófila Densa de terra firma - Amazônia Oriental. Revista Árvore, Viçosa, v. 30, n. 1, p. 49-54, 2006.

SPVS - SOCIEDADE DE PESQUISA EM VIDA SELVAGEM E EDUCAÇÃO AMBIENTAL. Plano de Manejo da Área Natural Protegida Morro da Mina. 1999.

TRIGO, L. G. G. Turismo, paisagem e ambiente. Bahia Análise \& Dados, Salvador, v. 11, n. 2, p. 146$152,2001$.

TUAN, Yi-Fu. Espaço e lugar: a perspectiva da experiência. Tradução: Lívia de Oliveira. São Paulo: Difel, 1983.

VARGAS, R. M. A.; SOUZA, M. J. M.; LOCH, C. Algumas considerações sobre a avaliação da paisagem na área de influência para implantação de hidrelétricas. In: Congresso Brasileiro de Cadastro Técnico Multifinalitário, Florianópolis, 2004. Anais... Universidade Federal de Santa Catarina, 2004.

XAVIER, H. Riscos da perda de identidade da paisagem rural. Revista de Turismo, Minas Gerais, v. 1, n. 1, p. 1-13, 2005. 